INFLAMMATORY BOWEL DISEASE

\title{
High prevalence of Mycobacterium avium subspecies paratuberculosis IS900 DNA in gut tissues from individuals with Crohn's disease
}

\author{
F Aułschbach, S Eisold, U Hinz, S Zinser, M Linnebacher, T Giese, T Löffler, M W Büchler, J Schmidt
}

Gut 2005;54:944-949. doi: 10.1136/gut.2004.045526

See end of article for authors' affiliations

Correspondence to:

Dr J Schmidt, Department of Surgery, University of Heidelberg, Im

Nevenheimer Feld 110, D-69120 Heidelberg, Germany; jan_schmidt@ med.uni-heidelberg.de

Revised version received 4 August 2004

Accepted for publication

31 August 2004
Background and aims: Conflicting results exist about the presence of Mycobacterium avium subspecies paratuberculosis (MAP) specific IS900 DNA in Crohn's disease (CD) tissues. Therefore, we examined IS900 in a large number of gut samples from patients with $C D(n=100)$ and ulcerative colitis (UC, $n=100$ ), and in non-inflamed control tissues ( $n I B D, n=100)$. We hypothesised that IS900 DNA detection might be associated with distinct clinical phenotypic characteristics in $C D$.

Methods: The prevalence of MAP DNA in surgically resected tissues was examined using a mechanicalenzymatic disruption technique and nested IS900 specific polymerase chain reaction (PCR). CD patients were stratified according to the criteria of the Vienna classification and other clinical characteristics.

Results: IS900 PCR detection rate was significantly higher in CD tissue samples (52\%) than in UC (2\%) or nIBD (5\%) specimens ( $p<0.0001)$. In CD patients, IS900 DNA was detected in samples from both diseased small bowel $(47 \%)$ as well as from the colon (61\%). No firm association between MAP specific IS 900 detection rates and clinical phenotypic characteristics in CD could be established. However, corticosteroid medication constituted a factor which tended to have a negative influence on IS900 DNA detection rates in $C D(p<0.01)$.

Conclusions: The presence of MAP specific IS900 DNA is a predominant feature of CD. Therapeutic intervention against MAP might represent a potential target for disease mitigation in Crohn's disease.

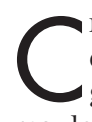

rohn's disease $(C D)$ is a chronic inflammatory bowel disease (IBD) of as yet unknown and possibly heterogeneous aetiology. Disturbances in intestinal immunoregulation as well as genetic factors are likely to be involved. However, a possible infectious aetiology has also been repeatedly discussed. In this respect, one of the most plausible candidates is Mycobacterium avium subspecies paratuberculosis (MAP). MAP represents a fastidious organism which can only rarely be detected by conventional microbiological techniques. The DNA sequence, IS900, first identified in 1989, ${ }^{1}$ is considered the gold standard in detecting and differentiating MAP from other types of bacteria/mycobacteria. ${ }^{2-4}$ However, discrepancies and experimental difficulties have surrounded the detection of MAP specific sequences by polymerase chain reaction (PCR) in IBD. Whereas several studies reported IS900 DNA to be present in gut tissues from a proportion of patients with $\mathrm{CD}^{\text {,- }}$ 9 others could not confirm such findings. ${ }^{10-14}$ In fact, the frequency of IS900 detection in bowel specimens is highly variable and ranges from $0 \%$ to $100 \%$ in ulcerative colitis (UC) and from $0 \%$ to $100 \%$ in CD. Furthermore, the sequence has also been found in gut tissues from control patients with diseases not specifically related to IBD (nIBD) $(0-87.5 \%){ }^{15}$ As a consequence of these technical difficulties, optimised PCR methods and specialised extraction procedures have been developed in an attempt to more reproducibly detect MAP DNA within tissue samples. ${ }^{16}$

In this study, our objective was to examine the detection rate of MAP in IBD patients using optimised tissue sample processing and a nested IS900 specific PCR. We analysed surgically resected transmural bowel tissues from a large number of cases with CD as well as UC and nIBD controls. Our results showed that the presence of MAP DNA within gut tissue reflects a phenomenon which is predominantly associated with CD.

\section{MATERIALS AND METHODS}

Patients and tissue samples

One hundred patients with CD, 100 patients with UC, and 100 patients with nIBD were included in the study. All patients underwent surgical resection of the small and/or large bowel segments for disease at the University Hospital, Heidelberg. The diagnoses of CD and UC were established by conventional clinical, radiological, and histological criteria. As nIBD controls, samples from patients resected for intestinal cancer, familiar adenomatous polyposis, and other non-IBD related conditions were used. In such patients, any form of IBD was excluded clinically and by histopathology. Procedures for subject recruitment and methods of human tissue analysis were in accordance with protocols approved by the ethics committee of Heidelberg University.

Clinical characteristics in CD patients were stratified according to the criteria of the Vienna classification ${ }^{17}$ and by other features. The respective Vienna classification status concerning age at diagnosis (A), location (L), and disease behaviour (B) was determined. Age was defined as the time when the diagnosis of $\mathrm{CD}$ was definitively established by radiology, endoscopy, pathology, or surgery. Location was defined as the maximum extent of disease involvement at any time before the first resection. Behaviour of disease referred to the indication for surgery, either stricturing disease or penetrating disease. Stricturing disease was defined as the occurrence of constant luminal narrowing without the presence of penetrating disease at any time during the course of the disease. A penetrating disease was based on the presence of intra-abdominal or perianal fistula,

Abbreviations: CD, Crohn's disease; MAP, Mycobacterium avium subspecies paratuberculosis; nIBD, non-inflammatory bowel disease; $I B D$, inflammatory bowel disease; IQR, interquartile range; PCR, polymerase chain reaction; RT, room temperature; UC, ulcerative colitis 
inflammatory mass, and/or abscess at any time during the course of the disease, even if there were coexisting strictures. Anoperineal lesions of CD were characterised by the presence of ulceration, fistula, abscess, and stricture. Excluded were perianal skintags. ${ }^{18}$ Further data were collected from patient charts and the Heidelberg Crohn registry.

Transmural tissue samples were obtained from macroscopically diseased intestine in each case of CD or UC. Two samples were analysed for each investigated site (small bowel/ileum or colon). In nIBD controls, transmural biopsies were taken from non-affected normal intestine. Samples were excised from tissue blocks which had been snap frozen by immersion in liquid nitrogen using a sterile scalpel. Samples were subsequently transferred to $1.5 \mathrm{ml}$ sterile screw tubes and labelled with a specific code number. Coded samples were randomly chosen for DNA extraction and PCR analysis in a blinded manner, with reagent and negative controls intercalated.

\section{DNA extraction}

The methodology for DNA extraction of MAP from resected bowel specimens has been previously described. ${ }^{16}$ Briefly, tissue samples were thawed and approximately 200-300 mg of each tissue were placed in a $1.5 \mathrm{ml}$ microcentrifuge tube containing $500 \mu \mathrm{l}$ sterile saline $(0.9 \% \mathrm{NaCl})$. After centrifugation at $10000 \times g$ for three minutes the pellet was resuspended in $600 \mu \mathrm{l}$ of mycobacterial lysis buffer $(2 \mathrm{mM}$ sodium EDTA, $400 \mathrm{mM} \mathrm{NaCl}, 10 \mathrm{mM}$ Tris $\mathrm{HCl}(\mathrm{pH} 8.0), 0.6 \%$ sodium dodecyl sulphate, and $33 \mu \mathrm{g} / \mathrm{ml}$ of proteinase $\mathrm{K}$ (Sigma, Deisenhofen, Germany)) and transferred to a blue capped Matrix B Ribolyser tube (Qbiogene, Heidelberg, Germany).The tubes were incubated at an angle of $45^{\circ}$ at $37^{\circ} \mathrm{C}$ overnight with gentle shaking. Following incubation, the tubes were chilled on ice for five minutes and mechanically disrupted using a Hybaid ribolyser machine (AGS, Heidelberg, Germany) at a setting of $6.5 / \mathrm{ms}^{2}$ for 45 seconds and then immediately chilled again on ice for at least 15 minutes. After consecutive extraction steps with equal volumes of phenol ( $\mathrm{pH} 6.7$, saturated in $1 \times \mathrm{TE}=10 \mathrm{mM}$ Tris HCL, $1 \mathrm{mM}$ sodium EDTA $(\mathrm{pH} \mathrm{8.0)})$, phenol-chloroform-isoamyl alcohol (25:24:1; Sigma, Germany), and chloroform-isoamyl alcohol (24:1) with intermediate centrifugation at $10000 \times \mathrm{g}$ for one minute, respectively, the final aqueous layer $(450 \mu \mathrm{l}$ ) was transferred to a new tube containing $90 \mu \mathrm{l}$ of $10 \mathrm{M}$ ammonium acetate and mixed thoroughly. DNA was then recovered by precipitation with $1 \mathrm{ml}$ of ice cold $100 \%$ ethanol at room temperature (RT) for one hour. DNA was pelleted by microcentrifugation, washed with $750 \mu$ l of ice cold $70 \%$ ethanol, air dried at RT for 30 minutes, and dissolved in $50 \mu \mathrm{l}$ of $1 \times$ TE. DNA concentration and purity was evaluated by UV absorption spectrophotometry. Extracted DNA samples were stored at $4{ }^{\circ} \mathrm{C}$ and used for PCR experiments within seven days.

\section{Mycobacterium paratuberculosis strain and plasmid}

As controls, we used a positive bacterial control consisting of $M$ paratuberculosis grown in Kirchner's medium which was kindly provided by Dr PTJ Willemsen (Laboratorium voor Mycobakteriele infecties Afdeling Bacteriologie, Amsterdam, the Netherlands). A positive DNA control, pIDL60, was a gift from T Bull (St George's Hospital, London). pIDL60 is made from a variant vector of the pcDNAII cloning series $(2.6 \mathrm{~kb}$ in length) and contains a $2.8 \mathrm{~kb}$ insert of $M$ paratuberculosis DNA, which includes a single copy of IS900.

\section{IS 900 specific nested PCR}

IS900 [L/AV] PCR specific for MAP was conducted as a nested primer PCR as previously described. ${ }^{16}$ Briefly, the first round PCR mixture comprised $5 \mu$ l of DNA sample extract in a final volume of $50 \mu \mathrm{l}$ with $2 \mu \mathrm{M}$ of each primer, Ll (5'-CTT TCT TGA AGG GTG TTC GG-3') and L2 (5'-ACG TGA CCT CGC CTC CAT-3'); $1 \times$ Expand High Fidelity reaction buffer containing $1.5 \mathrm{mM} \mathrm{mgCl}$, and $10 \%$ dimethyl sulphoxide; $200 \mu \mathrm{M}$ each of dATP, dGTP, dCTP, and dTTP; and $3.5 \mathrm{U}$ of Expand High Fidelity Taq polymerase (Expand High Fidelity PCR system; Roche, Mannheim, Germany). Reactions were cycled as follows: one cycle of $94^{\circ} \mathrm{C}$ for five minutes, then 30 cycles of $94^{\circ} \mathrm{C}$ for one minute, $58^{\circ} \mathrm{C}$ for one minute, and $72{ }^{\circ} \mathrm{C}$ for three minutes, followed by one cycle of $72^{\circ} \mathrm{C}$ for seven minutes.

Following primary PCR, all products were treated with $1 \mathrm{U}$ of uracil-DNA glycosylase ( $1 \mathrm{U} / \mu \mathrm{l}$; Roche) at RT for 10 minutes to eliminate PCR carryover contamination from any previous reactions. For the nested PCR, $5 \mu \mathrm{l}$ of the primary amplification were then used with the primers, AVI (5'-ATG TGG TTG CTG TGT TGG ATG G-3') and AV2 (5'-CCG CCG CAA TCA ACT CCA G-3') in a total volume of $50 \mu$ l. The PCR mix had the same ingredients as the primary reaction mixture except that $2 \mu \mathrm{M}$ of each primer AVl and AV2 was used and dTTP was replaced by $400 \mu \mathrm{M}$ dUTP. The cycling conditions were: one cycle of $94^{\circ} \mathrm{C}$ for five minutes, then 40 cycles of $94^{\circ} \mathrm{C}$ for one minute, $58^{\circ} \mathrm{C}$ for one minute, and $72^{\circ} \mathrm{C}$ for three minutes, followed by one cycle of $72^{\circ} \mathrm{C}$ for seven minutes. To prevent carryover contamination, extensive precautions were taken as described recently. ${ }^{16}$ PCR products were visualised with ethidium bromide on $1.5 \%$ agarose gels and the positive $298 \mathrm{bp}$ amplification products were sequenced in both directions using AV1 and AV2 as the sequencing primers. Samples shown to be IS900 negative were subsequently tested for PCR inhibition by repeating the

\begin{tabular}{|c|c|c|c|}
\hline & $C D$ & UC & nIBD \\
\hline $\mathrm{n}$ & 100 & 100 & 100 \\
\hline Age $(y)^{*}$ & $33.9(27-41)$ & $38.8(30-48)$ & $60.8(51-70)$ \\
\hline \multicolumn{4}{|c|}{ 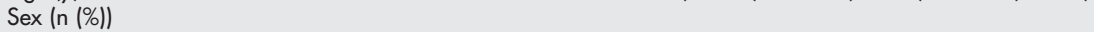 } \\
\hline Male & 40 & 55 & 58 \\
\hline Female & 60 & 45 & 42 \\
\hline Immunomodulation (n (\%)) & 76 & 80 & 0 \\
\hline \multicolumn{4}{|l|}{ Indication for surgery (n (\%)) } \\
\hline Stenosis/fistula/stenosis+fistula & $48 / 30 / 22$ & & \\
\hline Partial colitis/pancolitis/pancolitis+BWI & & $22 / 59 / 19$ & \\
\hline Colorectal cancer/FAP/pancreatic tumour/others $\dagger$ & & & $70 / 14 / 10 / 6$ \\
\hline
\end{tabular}

${ }^{*}$ Median (interquartile range)

†Three rectal adenomas, one chronic perithyphilitic process, one chronic pancreatitis, and one Meckel diverticulum.

BWI, backwash ileitis; FAP, familial adenomatosis polyposis coli. 
Table 2 Frequency of IS900 DNA detection in Crohn's disease (CD), ulcerative colitis (UC), and non-inflammatory (nIBD) controls

\begin{tabular}{|c|c|c|c|c|c|c|}
\hline & \multicolumn{2}{|l|}{$C D$} & \multicolumn{2}{|l|}{ UC } & \multicolumn{2}{|l|}{ nIBD } \\
\hline & $n$ & IS900 positive & $\mathbf{n}$ & IS900 positive & $\mathbf{n}$ & IS900 positive \\
\hline No of patients & 100 & 52 & 100 & 2 & 100 & 5 \\
\hline \multicolumn{7}{|l|}{ Site of investigated tissues } \\
\hline Small bowel/ileum & 64 & 30 & - & - & 23 & 1 \\
\hline Colon & 32 & 20 & 77 & 0 & 50 & 3 \\
\hline Rectum & 4 & 2 & 23 & 2 & 27 & 1 \\
\hline
\end{tabular}

PCR with the original DNA extract spiked with the control plasmid pIDL60.

\section{Statistical analysis}

Statistical analyses were performed using SAS software (release 8.02; SAS Institute Inc., Cary, North Carolina, USA). To compare MAP specific IS900 positive detection rates in the three groups $\mathrm{CD}, \mathrm{UC}$, and nIBD disease, Fisher's exact test was applied. Age differences between groups (median with interquartile range (IQR)) were compared using the Kruskal-Wallis test. A subgroup analysis of patients with CD was performed using the $\chi^{2}$ test, if appropriate, or Fisher's exact test, to analyse the association between the IS900 PCR results and clinical parameters of the Vienna classification (age, behaviour). The Cochran-Armitage trend test was used to analyse the association between location of $\mathrm{CD}$, classified as upper gastrointestinal, ileal, ileocolonic, and colonic manifestations, and IS900 PCR results. Other factors analysed by the $\chi^{2}$ test, if appropriate, or Fisher's exact test with respect to IS900 PCR results were sex, duration of disease, perianal disease, occurrence of granulomas, and corticosteroid medication. To calculate the association between clinical/biological disease characteristics and positive IS900 PCR results logistic regression analysis was performed. Odds ratio's with 95\% confidence intervals (CI) were given. Two sided p values were always computed and an effect was considered as statistically significant at a p value of $\leqslant .05$.

\section{RESULTS}

MAP specific IS 900 DNA detection in specimens from patients with $C D, U C$, and nIBD

IS900 nested PCR was performed with tissue samples from 100 patients with CD, 100 patients with UC, and 100 patients with nIBD. Clinical characteristics of the patients, including indication for surgery, in each study group are summarised in table 1. Median age was significantly higher in nIBD controls compared with CD or UC patients (median age 61 years $v 34$ and 39 years in $C D$ and UC; $p<0.0001$, respectively). There were more females among CD patients than in the UC or control groups $(p=0.0242)$. Median disease duration was 10 years in $C D$ and eight years in UC. At the time of sampling, $76 \mathrm{CD}$ patients and $80 \mathrm{UC}$ patients were being treated with corticosteroids and/or azathioprine while nIBD patients were not receiving immune suppressive medications. None of the patients received anti-MAP treatment with rifabutin or clarithromycin.

The results for IS900 DNA detection in the different study groups, including sites of tissue sampling, are shown in table 2. Detection rate of MAP specific IS900 DNA by PCR was considerably higher in patients with CD $(52 \%)$ compared with UC patients $(2 \%)$ and nIBD controls $(5 \%)(\mathrm{p}<0.0001$,

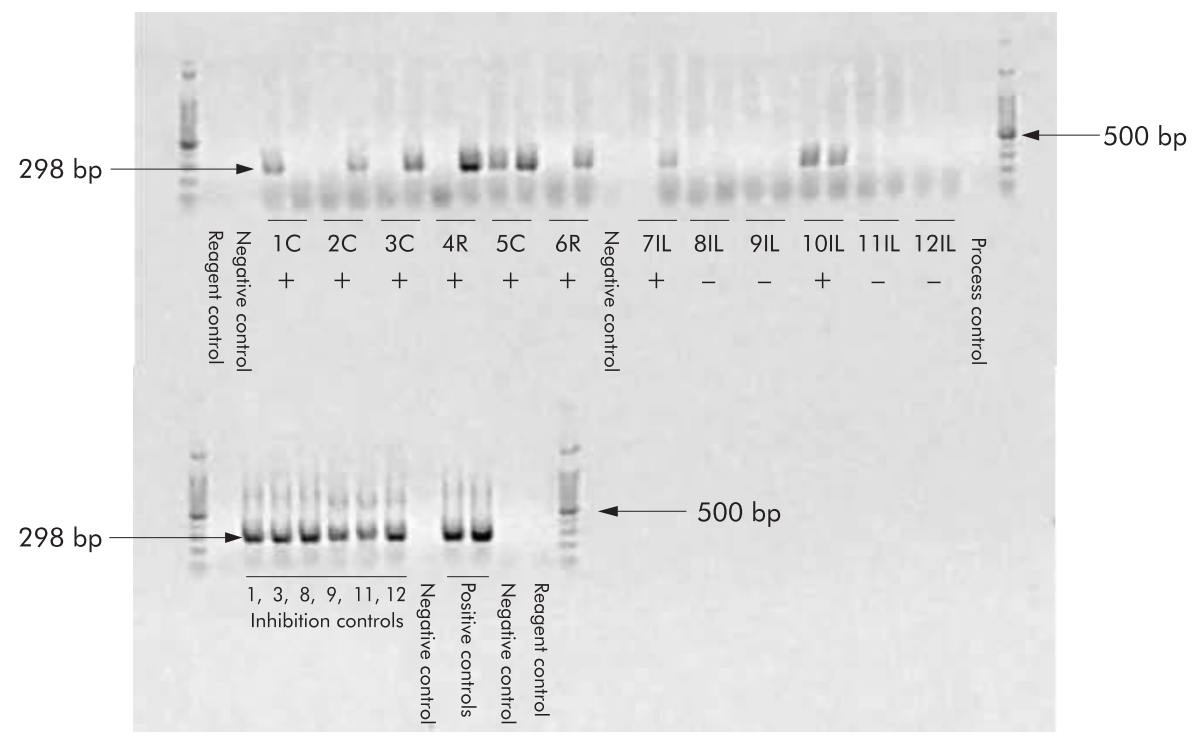

Figure 1 Agarose gel electrophoresis of polymerase chain reaction (PCR) products obtained from transmural bowel specimens following IS900 [L/ AV] nested PCR (Crohn's disease cases, two samples tested per case). Site of tissue sampling indicated as (C) colon, (R) rectum, and (IL) ileum. Lanes 1C, 2C, 3C, 4R, 5C, 6R, 7IL, 10IL, positive samples (+) with a specific amplification product of 298 bp. Lanes 8IL, 9IL, 11 IL, 12IL, negative samples (-). Note variation in band intensity of the amplified products on the gels. Regarding lanes $5 \mathrm{C}$ and 10IL, both samples were positive. Positive controls consisted of a plasmid (pIDL60) containing a single copy of IS900. Inhibition controls consisted of pIDL60 "spiked" into each sample after processing. 
Table 3 Statistical analysis of the association between IS900 polymerase chain reaction results and clinical features in 100 Crohn's disease patients

\begin{tabular}{|c|c|c|c|c|}
\hline Factor & $n$ & IS 900 positive & OR $(95 \% \mathrm{Cl})$ & p Value \\
\hline Sex & & & & 0.191 \\
\hline Male & 40 & 24 & 1 & \\
\hline Female & 60 & 28 & $0.583(0.26-1.30)$ & \\
\hline Duration of disease (y) & & & & 0.0392 \\
\hline$<15$ & 74 & 43 & 1 & \\
\hline$\geqslant 15$ & 26 & 9 & $0.382(0.15-0.95)$ & \\
\hline Age at diagnosis (y) (Vienna status) & & & & 0.322 \\
\hline$<40(\mathrm{~A} 1)$ & 90 & 45 & 1 & \\
\hline$\geqslant 40$ (A2) & 10 & 7 & $2.332(0.61-11.35)$ & \\
\hline Location (Vienna status) & & & & 0.0466 \\
\hline Upper GI (L4) & 2 & 1 & 1 & \\
\hline Terminal ileum (L1) & 42 & 17 & 1 & \\
\hline Ileocolon (L3) & 35 & 20 & $1.926(0.79-4.81)$ & \\
\hline Colon (L2) & 21 & 14 & $2.889(1.0-8.99)$ & \\
\hline Behaviour (Vienna status) & & & & 0.487 \\
\hline Stricturing (B2) & 22 & 10 & 1 & \\
\hline Penetrating (B3) & 78 & 42 & $1.400(0.54-3.69)$ & \\
\hline Perianal disease & & & & 0.0394 \\
\hline Yes & 33 & 22 & $2.466(1.05-6.05)$ & \\
\hline No & 67 & 30 & 1 & \\
\hline Granuloma & & & & 0.321 \\
\hline Yes & 49 & 23 & $0.671(0.30-1.47)$ & \\
\hline No & 51 & 29 & 1 & \\
\hline Corticosteroids & & & & 0.0097 \\
\hline Yes & 76 & 34 & $0.270(0.09-0.72)$ & \\
\hline No & 24 & 18 & 1 & \\
\hline
\end{tabular}

respectively). In the $\mathrm{CD}$ group, specimens tested positive by IS900 PCR were derived from the small bowel/ileum $(\mathrm{n}=30)$, colon $(n=20)$, and rectum $(n=2)$. In 18 of these cases $(35 \%)$, both transmural samples analysed for each site were found to be positive by IS900 PCR whereas in the remaining cases only one of two investigated samples proved to be positive. In the UC and nIBD group, only seven of 200 patients tested positive. The respective samples were derived from the rectum in UC $(n=2)$ and from the small bowel $(n=1)$, colon $(n=3)$, and rectum $(n=1)$ in nIBD. In all of these cases MAP DNA was detected in one of two investigated samples.

PCR amplification of MAP specific insertion sequence IS900 and subsequent agarose gel analysis of the amplified products showed a single band of 298 bp for positively tested tissue samples. As shown in fig 1, the PCR products differed in intensity. However, the amplicon sequences from the tested PCR products showed $100 \%$ identity with the IS900 sequence of MAP. All negative reagent and process controls were PCR negative, demonstrating the absence of contamination. All tissue samples that tested PCR negative by the IS900 PCR were retested after they were spiked with low IS900 copy number and were shown not to be inhibitory.

\section{IS900 DNA PCR results and clinical features in CD patients}

A possible association of MAP specific IS900 DNA detection with clinical features of $C D$ patients was investigated by stratification of $\mathrm{CD}$ cases according to the criteria of the Vienna classification system and other characteristics. Ethnicity of all $100 \mathrm{CD}$ patients was Caucasian and a family history of IBD in a first or second degree relative was reported in $10 \%$. Extraintestinal manifestations were documented in $16 \%$ of all cases. Table 3 summarises the MAP specific IS900 DNA PCR results and statistical data with respect to these subgroups.

No statistically significant associations were found with respect to sex, age at disease presentation $(<40$ years $v$ $>40$ years), and disease behaviour (stricturing $v$ penetrating). The presence or absence of granulomas within the resected specimens, as determined by conventional histopathology, had no significant influence on the PCR results.

A weak association was found between MAP specific IS900 detection rate and colonic/ileocolonic $(p=0.0466)$ as well as perianal disease involvement $(\mathrm{p}=0.0394)$. In this respect, CD patients with ileal disease revealed a lower IS900 detection rate $(40.5 \%)$ compared with those with colonic $(66.7 \%)$ or ileocolonic disease manifestations (57.1\%). Furthermore, the frequency of MAP DNA detection tended to be decreased in patients with a disease duration of longer than 15 years ( $>75 \%$ percentile of median disease duration) $(p=0.0392)$ and in individuals receiving corticosteroids at the time of resection $(\mathrm{p}=0.0097)$.

\section{DISCUSSION}

A disturbance in intestinal immunoregulation with development of an exaggerated immune response against components of the enteric microflora is thought to be implicated in the pathogenesis of CD. Epidemiological and linkage studies suggest that genetic factors play a significant role in determining disease susceptibility, and a variety of genes have been postulated to be involved. ${ }^{19}$ For example, one of the best replicated linkage regions, IBDI on chromosome 16q, contains the Crohn's related gene NOD-2/CARD15 which is involved in host resistance to microbial pathogens. ${ }^{20}{ }^{21}$ Mutations of NOD-2 are observed in approximately $8-17 \%$ of CD patients and are associated with an early disease onset, ileal location, and a stricturing phenotype. ${ }^{22}$ While such data basically support a role for enteric microorganisms in $\mathrm{CD}$, the question of a possible infectious agent causing the disease is controversial. The chronic granulomatous type of inflammation that is characteristic of $\mathrm{CD}$ has long led to speculations that an unusual intracellular or slowly replicating microorganism may be involved. In this context, there are increasingly compelling data that MAP, a major cause of chronic IBD in agricultural, domestic, and wild animals, might also play a role in the pathogenesis of human CD. Promising results in this respect come from trials that include macrolide antibiotics and indicate that a cure for CD by such treatment might be possible..$^{23-26}$ 
In this study we explored the detection rate of MAP in transmural samples of the gut in a large group of patients with CD as well as UC and nIBD controls. IS900 PCR analysis revealed that MAP IS900 DNA is detectable in a high percentage of tissues from patients with CD $(>50 \%)$ whereas it is uncommon in UC or nIBD controls $(<5 \%)$. Although the presence of DNA does not constitute proof that MAP causes $\mathrm{CD}$, our results confirm that MAP detection is a relatively specific feature of CD rather than UC or non-IBD controls. Our results thus support findings from other studies which detected IS900 DNA in a proportion of cases with CD. ${ }^{5-9} 16$ 27-29

However, the published reports reveal a striking variability in IS900 detection rates, which also include negative findings. ${ }^{10-14} 30$ This phenomenon is most likely caused by methodological differences in study design and detection procedures. One of the major difficulties of working with this organism is its slow growing nature and the complexity of the cell wall. It has been postulated that MAP IS900 DNA in $\mathrm{CD}$ is present in low abundance within the tissues and that the microorganism occurs in a tough $\mathrm{ZN}$ negative lysis resistant form putatively coated with methylated and acetylated fucose. ${ }^{30}{ }^{31}$ These features can cause inability to effectively extract DNA from the mycobacteria. Furthermore, MAP is thought to reside within the extranuclear body of infected cells, probably in the phagosome. However, some commercial DNA isolation kits may remove all of the nonnuclear cellular organelles with the consequence of false negative results. ${ }^{32}$ Therefore, specialised extraction procedures, including mechanical-enzymatic techniques of tissue disruption as well as standardised PCR protocols, are necessary to reproducibly detect MAP DNA from tissues. Confidence in the results of the present study was ensured by rigorous testing, as described above. However, even with our optimised protocol, negative test results in individual samples from a given MAP positive patient do occur. Apart from technical reasons, heterogeneous distribution of MAP sequences within the tissue might be of relevance in this respect.

In two recent studies on MAP in IBD, the control groups were reported to have MAP DNA in approximately 30\% of cases, in contrast with our results. ${ }^{40}$ Using a population based approach, Bernstein et al investigated colonoscopic biopsies and were unable to detect MAP DNA in any of the investigated 24 cases with CD but in six of 19 healthy control patients $(32 \%)$ and in one of 28 UC patients. ${ }^{30}$ However, as discussed by these authors, their use of a standard DNA extraction technique rather facilitates the detection of the vegative form of MAP but may have led to non-detection of the lysis resistant paucibacillary form which is postulated to reside in the intestines of CD patients. ${ }^{30}$ Thus differences in methodology may in part explain the differences from our results.

Using a similar technical approach as in our study, Bull et al investigated a series of freshly obtained mucosal biopsies from individuals with CD and controls. ${ }^{4}$ In this study, MAP DNA was found in a significantly higher percentage of CD cases ( 34 of 37 patients; $92 \%$ ) compared with controls, which is in line with our results. However, $26 \%$ of individuals in the nIBD control group (9/34) were positive for MAP DNA (cases with UC were not investigated). The use of freshly processed non-frozen mucosal samples may be one possible reason for the relatively high percentage of positive cases in both groups compared with our data. However, as the authors point out, the control group in this study did not represent a healthy population but comprised patients undergoing ileocolonoscopy for diverse reasons who did not have an established diagnosis of $\mathrm{CD}$, including conditions such as irritable bowel syndrome, suspected ischaemia, lymphocytic colitis, and human immunodeficiency virus infection. This is in contrast with our nIBD control group which comprised a large number of samples from non-involved gut from patients with colorectal or other tumours in which IBD was excluded clinically and by histopathology. Discrepant detection rates might be influenced by such conditions and the choice of material (mucosal or transmural) may also have affected the results. In this context, no information on morphology of the investigated samples was given in the study by Bernstein and colleagues. $^{30}$

Concerning the investigated clinical features, our results did not reveal any firm association between MAP detection rates and disease phenotype in CD. Some weak statistical associations were found between MAP specific IS900 detection rate and colonic/ileocolonic as well as perianal disease involvement. Although these associations were weak, it should be emphasised that the detection rate of MAP in CD was equivalent and in fact even somewhat higher in colonic compared with ileal samples (47\% and $61 \%$, respectively). This clearly indicates that differences in MAP detection rates between CD and UC cannot be attributed to different tissue sources. The elevated frequency of IS900 DNA in colonic specimens of CD, but not in colonic samples of patients with $\mathrm{UC}$, is striking and is likely to reflect a phenomenon specifically related to $\mathrm{CD}$ in this context. In agreement with the results observed by other investigators, we found the IS900 sequence to be prevalent in CD tissue samples regardless of the presence of granulomas. ${ }^{29} 33$

Two clinical factors tended to be associated with a rather decreased MAP specific IS900 DNA detection rate within the tissue specimens-namely, a disease duration of more than 15 years (weak significance) and corticosteroid treatment at the time of resection. The reasons for these findings are unclear at present. It might be speculated that the slow growing nature of MAP and chronic interference with the intestinal immune system could affect the amount of microorganisms within the tissue in long term disease. Apart from this, immune modulation with corticosteroids may interfere with tissue mediators affecting the in vivo growth of MAP.

In conclusion, our results confirm that detection of MAP specific IS900 DNA is a predominant feature of CD rather than UC or non-IBD controls. Therapeutic intervention against MAP may be a potential target for disease mitigation in Crohn's disease.

\section{ACKNOWLEDGEMENTS}

This work was supported by the Deutsche Forschungsgemeinschaft (SFB 405, project B6).

\section{Authors' affiliations \\ F Autschbach*, Institute of Pathology, University of Heidelberg, Germany \\ S Eisold*, Department of General, Thoracic, and Vascular Surgery, University of Rostock, Germany \\ U Hinz, Unit for Documentation and Statistics, University of Heidelberg, Germany \\ S Zinser, T Löffler, M W Büchler, J Schmidt, Department of General Surgery, University of Heidelberg, Germany \\ M Linnebacher, Molecular Pathology, University of Heidelberg, Germany \\ T Giese, Institute of Immunology, University of Heidelberg, Germany}

*F Autschbach and S Eisold contributed equally to this paper.

Conflict of interest: None declared.

\section{REFERENCES}

1 Green EP, Tizard ML, Moss MT, et al. Sequence and characteristics of IS900, an insertion element identified in a human Crohn's disease isolate of Mycobacterium paratuberculosis. Nucleic Acids Res 1989;17:9063-73. 
2 Naser SA, Schwartz D, Shafran I. Isolation of Mycobacterium avium subsp paratuberculosis from breast milk of Crohn's disease patients. Am J Gastroenterol 2000;95:1094-5.

3 Hulten K, Karttunen TJ, El-Zimaity HM, et al. Identification of cell wall deficient forms of $M$. avium subsp. paratuberculosis in paraffin embedded tissues from animals with Johne's disease by in situ hybridization. J Microbiol Methods 2000;42: 185-95.

4 Bull TJ, Hermon-Taylor J, Pavlik I, et al. Characterization of IS900 loci in mycobacterium avium subsp. paratuberculosis and development of multiplex PCR typing. Microbiology 2000; 146:3285.

5 Sanderson JD, Moss MT, Tizard ML, et al. Mycobacterium paratuberculosis DNA in Crohn's disease tissue. Gut 1992;33:890-6.

6 Lisby G, Andersen J, Engbaek K, et al. Mycobacterium paratuberculosis in intestinal tissue from patients with Crohn's disease demonstrated by a nested primer polymerase chain reaction. ScandGastroenterol 1994;29:923-9.

7 Erasmus DL, Victor TC, van Eeden PJ, et al. Mycobacterium paratuberculosis and Crohn's disease. Gut 1995;36:942.

8 Schwartz D, Shafran I, Romero C, et al. Use of short-term culture for identification of Mycobacterium avium subsp. paratuberculosis in tissue from Crohn's disease patients. Clin Microbiol Infect 2000;6:303-7.

9 Collins MT, Lisby G, Moser C, et al. Results of multiple diagnostic tests for Mycobacterium avium subsp. paratuberculosis in patients with inflammatory bowel disease and in controls. J Clin Microbiol 2000;38:4373-81.

10 Rowbotham DS, Mapstone NP, Trejdosiewicz LK, et al. Mycobacterium paratuberculosis DNA not detected in Crohn's disease tissue by fluorescent polymerase chain reaction. Gut 1995;37:660-7.

11 Frank TS, Cook SM. Analysis of paraffin sections of Crohn's disease for Mycobacterium paratuberculosis using polymerase chain reaction. Mod Pathol 1996:9:32-5.

12 Clarkston WK, Presti ME, Petersen PF, et al. Role of Mycobacterium paratuberculosis in Crohn's disease: a prospective, controlled study using polymerase chain reaction. Dis Colon Rectum 1998:41:195-9.

13 Chiba M, Fukushima T, Horie $Y$, et al. No Mycobacterium paratuberculosis detected in intestinal tissue, including Peyer's patches and lymph follicles, of Crohn's disease. J Gastroenterol 1998;33:482-7.

14 Kanazawa K, Haga Y, Funakoshi O, et al. Absence of Mycobacterium paratuberculosis DNA in intestinal tissues from Crohn's disease by nested polymerase chain reaction. J Gastroenterol 1999;34:200-6.

15 Quirke P. Antagonist. Mycobacterium avium subspecies paratuberculosis is a cause of Crohn's disease. Gut 2001;49:757-60.

16 Bull TJ, McMinn EJ, Sidi-Boumedine K, et al. Detection and verification of Mycobacterium avium subsp. paratuberculosis in fresh ileocolonic mucosal biopsy specimens from individuals with and without Crohn's disease. J Clin Microbiol 2003;41:2915-23.

17 Gasche C, Scholmerich J, Brynskov J, et al. A simple classification of Crohn's disease: report of the Working Party for the World
Congresses of Gastroenterology, Vienna 1998. Inflamm Bowel Dis 2000;6:8-15

18 Pikarsky AJ, Gervaz P, Wexner SD. Perianal Crohn disease: a new scoring system to evaluate and predict outcome of surgical intervention. Arch Surg 2002;137:774-7.

19 Bonen DK, Cho JH. The genetics of inflammatory bowel disease. Gastroenterology 2003; 124:521-36.

20 Hugot JP, Chamaillard M, Zouali H, et al. Association of NOD2 leucine-rich repeat variants with susceptibility to Crohn's disease. Nature 2001;411:599-603.

21 Ogura $\mathrm{Y}$, Bonen DK, Inohara N, et al. A frameshift mutation in NOD2 associated with susceptibility to Crohn's disease. Nature 2001;41 1:603-6.

22 Cuthbert AP, Fisher SA, Mirza MM, et al. The contribution of NOD2 gene mutations to the risk and site of disease in inflammatory bowel disease. Gastroenterology 2002; 122:867-74.

23 Gui GP, Thomas PR, Tizard ML, et al. Two-year-outcomes analysis of Crohn's disease treated with rifabutin and macrolide antibiotics. J Antimicrob Chemother 1997;39:393-400.

24 Douglass A, Cann PA, Bramble MG. An open pilot study of antimicrobial therapy in patients with unresponsive Crohn's disease. Gut 2000;46:A1 1

25 Borody TJ, Leis S, Warren EF, et al. Treatment of severe Crohn's disease using antimycobacterial triple therapy--approaching a cure? Dig Liver Dis 2002;34:29-38.

26 Shafran I, Kugler L, El-Zaatari FA, et al. Open clinical trial of rifabutin and clarithromycin therapy in Crohn's disease. Dig Liver Dis 2002;34:22-8.

27 Ikonomopoulos JA, Gorgoulis VG, Kastrinakis NG, et al. Sensitive differential detection of genetically related mycobacterial pathogens in archival material. Am J Clin Pathol 2000;1 14:940-50.

28 Hulten K, El-Zimaity HM, Karttunen TJ, et al. Detection of Mycobacterium avium subspecies paratuberculosis in Crohn's diseased tissues by in situ hybridization. Am J Gastroenterol 2001;96:1529-35.

29 Ryan P, Bennett MW, Aarons S, et al. PCR detection of Mycobacterium paratuberculosis in Crohn's disease granulomas isolated by laser capture microdissection. Gut 2002;51:665-70.

30 Bernstein CN, Nayar G, Hamel A, et al. Study of animal-borne infections in the mucosas of patients with inflammatory bowel disease and populationbased controls. J Clin Microbiol 2003:41:4986-90.

31 Hermon-Taylor J, Bull TJ, Sheridan JM, et al. Causation of Crohn's disease by Mycobacterium avium subspecies paratuberculosis. Can J Gastroenterol 2000;14:521-39

32 Greenstein RJ. Is Crohn's disease caused by a mycobacterium? Comparisons with leprosy, tuberculosis, and Johne's disease. Lancet Infect Dis 2003:3:507-14.

33 Sechi LA, Mura M, Tanda F, et al. Identification of Mycobacterium avium subsp. paratuberculosis in biopsy specimens from patients with Crohn's disease identified by in situ hybridization. J Clin Microbiol 2001;39:4514-7

\section{EDITOR'S QUIZ: GI SNAPSHOT}

\begin{abstract}
Answer
From question on page 943

Rectal biopsies showed lymphoid follicle hyperplasia and diffuse inflammatory infiltrate with lymphocytes and neutrophils. Enzyme immunoassay of chlamydial antigens in the rectal biopsies and specific serum immunoglobulin $G$ antibodies revealed Chlamydia trachomatis infection. Her partner also had $C$ trachomatis urethritis. A diagnosis of $C$ trachomatis proctitis was made. Her symptoms improved with oral minocycline for two weeks. Follow up colonoscopy two months later showed that granular proctitis had completely healed without scar formation.

Sexually transmitted gastrointestinal syndromes, caused by $\mathrm{C}$ trachomatis, Treponema pallidum, Neisseria gonorrhoeae, Entamoeba histolytica, and herpes simplex virus, include proctitis and proctocolitis. Unprotected anal intercourse may increase the risk of this infection. C trachomatis causes trachoma, oculogenital infections, and lymphogranuloma venereum in humans. The word trachomatis is derived from the Greek word, translated as roughness, and refers to the characteristic conjunctival follicles, which have a similar appearance to granular proctitis.

In conclusion, sexually transmitted proctitis should be included in the differential diagnosis of anorectal inflammation and a careful history may provide important clues to direct appropriate specimen collection.
\end{abstract}

doi: 10.1136/gut.2004.061424 